
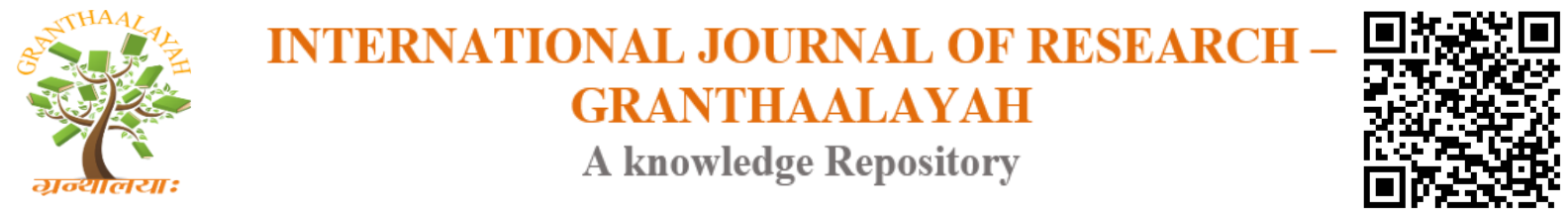

Management

\title{
TRAINING ON WATER, SANITATION, AND HYGIENE (WASH) TO THE FRONTLINE WORKERS (FLWS) IN A RURAL SET UP
}

\author{
Shyama Prasad Chattopadhyay ${ }^{* 1}$ \\ ${ }^{* 1}$ MA(Economics), MBA, Assistant Professor, IIHMR University, Jaipur, Rajasthan, India
}

\begin{abstract}
Water and Sanitation is one of the primary drivers of public health. Poor hygiene, inadequate quantities and quality of drinking water and lack of sanitation facilities cause millions of the India's poorest people to die from preventable diseases each year. The MPTAST has been extending technical assistance to the State Government of Madhya Pradesh to improve their water, sanitation, and hygiene (WASH) planning, delivery, and monitoring mechanisms, and to accelerate the sanitation coverage through a community-led approach. One of the key components of technical assistance under the WASH program was to provide training to Front Line Workers (FLWs) as they play an important role to assist the communities in raising awareness \& motivation. This awareness \& motivation of the community members would be created a demand for WASH services to access \& leverage govt. support schemes and funds under the Govt. of India flagship program "Swachh Bharat Mission". The IIHMR on behalf of MPWASH were organized district/block/ cluster/section wise training of FLWs in selected 7 Districts of Eastern Madhya Pradesh and covered around 98\% of target. It was expected that WASH training to FLWs will bring lot of positive changes in orientation \& motivating the community people at Village level.
\end{abstract}

Keywords: Water; Sanitation; Hygiene; Coverage; Training; Awareness \& Motivation.

Cite This Article: Shyama Prasad Chattopadhyay. (2017). "TRAINING ON WATER, SANITATION, AND HYGIENE (WASH) TO THE FRONTLINE WORKERS (FLWS) IN A RURAL SET UP." International Journal of Research - Granthaalayah, 5(8), 175-184. https://doi.org/10.29121/granthaalayah.v5.i8.2017.2207.

\section{Introduction}

The Department of International Development (DFID) in India was extended technical assistance to the State Government of Madhya Pradesh includes support to the Panchayat Raj and Rural Development (PR\&RD) and Public Health Engineering Department (PHED) to improve their water, sanitation, and hygiene (WASH) planning, delivery, and monitoring mechanisms and to accelerate the sanitation coverage through a community-led approach. The objective of WASH component of MPTAST was to promote skills, systems, and sustainable services with attention on safe, equitable, inclusive, and sustainable access to water supply, sanitation services and 
improved hygiene behaviors. The program focused was empowering citizens to access and leverage existing government support schemes and funds, and developing the capacity of the government staff on addressing current 'bottlenecks'. At state level, MPWASH team were worked with concerned departments of Govt. of Madhya Pradesh (i.e. PHED and Rural Development Department) to identify problem areas and provide technical assistance to improve WASH planning, budget utilization and strengthen WASH delivery at state and certain priority districts. One of the important components of the program was to develop the capacity of the Frontline Workers to create greater community awareness and action on WASH. The program was involved training Frontline Workers i.e. Accredited Social Health Activist (ASHA) and Anganwadi Workers(AWW) in these districts to help integrate WASH in their core activities. On behalf of MPWASH, IIHMR University, Jaipur were roll out the training of FLWs on WASH mainly all the ASHAs \& part of AWW in seven eastern rural districts of MP namely Satna, Chhatarpur, Sidhi, Rewa, Damoh, Jabalpur and Mandla.

\section{Objective}

It was observed through different Health \& Nutrition program of State Health Society, Madhya Pradesh that the Frontline workers were played an important role to assist communities in raising their awareness and motivation. It was assumed that the training on WASH to the Frontline Workers mainly ASHA and AWW would be helpful to disseminate the learning's to the community, create greater awareness on WASH issues and help to change behavioral aspects on it. These trained frontline workers on WASH would be instrumental to motivate the community members towards achieving the objectives of "Swachh Bharat Mission". It was also envisaged that WASH training intervention will also lead to:

- Building capacities of Frontline workers to support implementation of WASH programme in the semi urban and rural areas of the districts.

- Improve knowledge, increase demand, and access for WASH services through community mobilisation processes.

- Strengthen linkages with government service providers to ensure access to quality WASH services.

The WASH training program for FLWs mainly ASHA and AWWs in 7 highly MPTAST focused Districts were carried out by IIHMR University team during May-August 2015. The trainings were organized in block/cluster/sector(village) level and the venues were either CHC/Panchayat Bhavna/AWW premises etc.

\section{Material \& Methods}

To provide WASH training to FLWs at rural set up in economically backward districts of eastern Madhya Pradesh, IIHMR University, Jaipur organized number of activities to make the WASH training effective and helpful to achieve the prime objectives of the WASH components of the MPTAST.

Develop Training Module \& Handbook: The IIHMR project team were developed the standard training Module in Hindi version on WASH contents \& guidelines for the trainers as well as trainees. The two modules i.e. one for the 2 days training of trainers (ToT) and another 
for 1-day field level training of FLWs based on the existing module of MPWASH. The contents of the modules were on training pedagogy using adult learning techniques and key messages under each broad WASH content area. The existing modules of MPWASH were customized by the IIHMR University team with the support of "WaterAid", the partner organization of MPTAST looking after the WASH. To make the WASH training more useful and effective, the IIHMR University team with consultation with WaterAid developed a Handbook for the trainees (FLWs) with relevant information on WASH subject. The printed Handbook on WASH subjects was shared at the end of the training to all the trainees as a reference material.

Training of Trainers (ToT): To provide training of a sizeable numbers of Frontline Workers on WASH especially ASHA \& AWW workers in 7 Districts of MP, IIHMR University, Jaipur was developed a training cadre dedicated for the WASH training program. The IIHMR University organized a 3 days intensive Training of Trainers (ToT) program to enhance the training capacity of the selected trainers on WASH and related issues with the technical support of MPWASH in Jabalpur, Madhya Pradesh on 11-13 May, 2015. The program was completed successfully as per the planned schedule and methodology. To understand the impact of the ToT, a pre-post evaluation was carried out to understand training impact on the trainees and the change results were analyzed. To ensure the quality of the trainers, the IIHMR team members with the help of MPWASH were evaluated the trainees on various aspects like understanding of the subject, methodology, adult learning techniques, management of training etc.

Develop Training Plan: The one-day training plan/Calendar for the FLWs at the block/cluster level were developed in advance based on the total strength of FLWs available in that area i.e. ASHA and AWW. The data base of State Health Society, MP for ASHA workers \& Department of Women \& Child Development for AWW, MP were used to finalized target number of trainees in the specific target Districts. During the finalization of training plan, the two important things considered were 1) size of the trainees' batch (ASHA) within the range of maximum 40 and minimum 20 and for AWW, on availability at sector level i.e. around 25 \& 2) training program was not organized on Tuesday i.e. the immunization day and Sunday as holiday. The training calendars were shared with the National Health Mission, Govt. of M.P. ASHA Cell \& Directorate of Women \& Child Development, M.P. for their approval and further communicate to the District and Block officials for their permission to make FLWs available on the training day \& time.

Implementation of Training: The 28 trainers were selected after the Training of Trainers (ToT) and divided in two groups of 14 members each for a District. It was in the work plan that one group comprised of 7 teams ( 2 members in a team) will implement training in 7 blocks of one district and another group will implement training in another district. This arrangement was helpful to work simultaneously in 2 districts to complete the district targets in a reasonable time. The training program of FLWs started on $14^{\text {th }}$ May, 2015 and completed in $25^{\text {th }}$ August, 2015. The trainers were covered 42 blocks training with 8098 ASHAs in 7 Districts namely Satna, Chattarpur, Sidhi, Rewa, Damoh, Jabalpur and Mandla. The trainers team were also completed the training of 6674 AWW members in the districts of Damoh, Jabalpur, Satna \& Chattarpur .

Quality Issues: To made the training program more acceptable and comfortable to the FLWs at ground level in district/blocks/sectors of the mentioned 7 districts of Madhya Pradesh, all the 
training instruments, study materials and medium of language used for communication by trainers were in local language i.e. in Hindi. To ensure the quality of the training, the IIHMR University field staffs were involved in regular monitoring of the field level training, participating one or two sessions of the training and analysis of pre $\&$ post test data of the trainees.

It was decided in the planning period that use of modern training methods of using tools like power point presentation \& computer records are not possible due to non-availability of electricity and other structural issues in rural set up. To maintained the standard protocol considering the natural hindrance of the training at grass root level, the IIHMR University team in consultation with the MP WASH were developed the teaching aids i.e. Flip Chart, a visual aid consisting of a large flex print, comprising the information of WASH training contents. It was an immense helpful for the trainers to follow the standard training protocol using the training aids. It was also helpful for the trainees to have glimpse over the entire training subjects during training as the poster was placed in the walls of the training hall. The IIHMR University team were also developed the "Trainers Feedback" checklist to understand the local issues on WASH and other important factors relevant to improve the training quality on WASH to FLWs. The trainers' feedback was analyzed and the important points recorded for comments, suggestions, and recommendations.

The IIHMR University team with the support of MP WASH were also reviewed the performance of the trainers after completion of a district training based on the field level observation on the certain parameters like clarity on deliberation, use of teaching/training tools, capacity to involve the participants in the process etc. The IIHMR University team members \& MPWASH were also jointly organized 3 different performance reviews cum refresher training to enhance the capacity for the trainers during the FLWs training period., The team composition was changed time to time to get the best combination of trainers to improve of the quality of WASH training based on the trainers' performance observation.

\section{Status of Wash on 7 Districts}

The IIHMR University team members were covered WASH training in 7 districts of ASHA workers in first phase and AWWs of 4 districts in second phase. One of the objectives in the training was to review the existing status of WASH in the rural community for creating awareness among trainees. The status of WASH practices was found poor at village level as communicated to the trainers by ASHA \& AWWs in during the training session.

The different aspects of WASH status communicated during the training sessions were: 1) The general awareness of the community is very less and people are casual on WASH issues \& its application in day to day life 2) Water is not available in sufficient quantity in the entire districts especially in summer and to some extent in winter also 3) The socio-economic status of the rural community is poor and unable to maintain the cleanliness of Hand Pumps, Well etc. 4) Shortage of Water is the main hindrance in constructing toilets 5) Drainage system is poor and even certain areas drainage system exist not at all 6) Toilet constructed by panchayat is not up to the mark under "Swachh Bharat Mission" and newly constructed toilets are not used by the community members 7) Mostly places the sarpanch is not supportive to promote the toilets at 
individual house and even not disclose about the funds received by the panchayat as a subsidy for constructing toilets at home 8) In the monsoon season, the supply water contains mud and very little action was taken by responsible government officials 9) Certain areas water quality is poor. It is salty in taste and color is grey due to excessive iron in the water.

\section{Result \& Discussion}

The $1^{\text {st }}$ round training in 7 districts by blocks/cluster specially for the ASHA were completed by the IIHMR University field team with the support of ASHA cell, State Health Society, Madhya Pradesh along with their districts/blocks officials and MPWASH team members. The total ASHA trained shown in Table 1(a) in 7 Districts were 8098, which is around 79 percent of the target i.e. 10270. The main reason for the moderate coverage was due to the availability of functional ASHA in the block level against the records in State Health Society, MP, Bhopal. The less coverage in Rewa \& Mandla districts were due to distance of the block headquarters where training was organized and non-availability of transport at village/block level.

\begin{tabular}{|l|l|l|l|}
\hline \multicolumn{5}{|c|}{ Table 1(a): ASHA trained under the Program } \\
\hline District & ASHA Target & ASHA Trained & Achievement (\%) \\
\hline Satna & 1985 & 1539 & 77.5 \\
\hline Chhatarpur & 1460 & 1109 & 76.0 \\
\hline Rewa & 2081 & 1491 & 71.6 \\
\hline Sidhi & 1175 & 941 & 80.1 \\
\hline Jabalpur & 1209 & 1105 & 91.4 \\
\hline Mandala & 1177 & 857 & 72.8 \\
\hline Damoh & 1183 & 1056 & 89.3 \\
\hline Grand Total & $\mathbf{1 0 2 7 0}$ & $\mathbf{8 0 9 8}$ & $\mathbf{7 8 . 9}$ \\
\hline
\end{tabular}

The IIHMR University field team in second round trained the FLWs mainly AWW in 4 high focused districts in terms of low socio-economic \& health indicators i.e. Satna, Chhatarpur, Jabalpur and Damoh. The training of AWWs were organized at sector level comprising of 3-4 panchayats under a block of a districts. The training program on WASH for AWWs were halted twice due to special program of Women \& Child Development, Madhya Pradesh. The revised programs were implemented by the IIHMR University team with the support of district \& block program officials and completed the target AWWs training. The achievement rate as shown in Table 1(b) was quite reasonable against the target i.e. 93.4 percent.

\begin{tabular}{|l|l|l|l|}
\hline \multicolumn{4}{|c|}{ Table 1(b): AWW trained under the Program } \\
\hline District & AWW Target & AWW Trained & Achievement (\%) \\
\hline Satna & 2468 & 2312 & 93.7 \\
\hline Chattarpur & 1585 & 1585 & 100.0 \\
\hline Jabalpur & 1526 & 1449 & 95.0 \\
\hline Damoh & 1815 & 1328 & 73.2 \\
\hline Grand Total & $\mathbf{7 1 4 7}$ & $\mathbf{6 6 7 4}$ & $\mathbf{9 3 . 4}$ \\
\hline
\end{tabular}


To stop the practice of open defecation at the village level was one of the important objective under the campaign "Swacch Bharat Mission" and one of the important agenda for discussion under the program. The purpose of the WASH training to ASHA workers and other Frontline Community Worker at village level was to aware, motivate \& promote the community members to promote the healthy environment by reducing the water born \& other diseases related to cleanliness. The training of FLWs on WASH were organized based on the assumption that to made them become the role model of the community to spread the knowledge on WASH. Their personal belonging of toilets and its use will be added helpful to promote, built, and use of toilets in the community. In this direction, the status of toilets at home and its usage were also recorded during the training session. It was found in Table 2(a) that 47 percent out of total 8098 ASHA trained were the toilets in their house and use on regular basis. The status of household toilet of ASHAs in Sidhi, Mandla \& Damoh Districts were comparatively less and it was explored that these ASHAs were from remote villages compare to the other districts.

\begin{tabular}{|l|l|l|l|l|}
\hline \multicolumn{5}{|l|}{ Table 2(a): Status of Toilet in ASHAs House trained under WASH program } \\
\hline District Name & With Toilet & Without Toilet & Total & \% with Toilet \\
\hline Satana & 811 & 728 & 1539 & 52.7 \\
\hline Rewa & 843 & 648 & 1491 & 56.5 \\
\hline Chhatarpur & 571 & 538 & 1109 & 51.5 \\
\hline Sidhi & 296 & 645 & 941 & 31.5 \\
\hline Jabalpur & 623 & 482 & 1105 & 56.4 \\
\hline Mandla & 219 & 638 & 857 & 25.6 \\
\hline Damoh & 442 & 614 & 1056 & 41.9 \\
\hline Overall & $\mathbf{3 8 0 5}$ & $\mathbf{4 2 9 3}$ & $\mathbf{8 0 9 8}$ & $\mathbf{4 7 . 0}$ \\
\hline
\end{tabular}

The status of availability of toilets to the AWWs house was quite impressive as shown in Table 2(b) compare to ASHAs trained on WASH in the $1^{\text {st }}$ round on same subject.

\begin{tabular}{|l|l|l|l|l|}
\hline \multicolumn{4}{|l|}{ Table 2(b): Status of Toilet in AWWs House trained under WASH program } \\
\hline District Name & With Toilet & Without Toilet & Total & \% with Toilet \\
\hline Satana & 1652 & 660 & 2312 & 71.5 \\
\hline Chhatarpur & 1118 & 467 & 1585 & 70.5 \\
\hline Jabalpur & 1295 & 154 & 1449 & 89.4 \\
\hline Damoh & 757 & 571 & 1328 & 57.0 \\
\hline Over all & $\mathbf{4 8 2 2}$ & $\mathbf{1 8 5 2}$ & $\mathbf{6 6 7 4}$ & 72.3 \\
\hline
\end{tabular}

The trainers were organized Pre \& Post test in every 1 day WASH training for ASHA as well as AWW to record the knowledge level of the trainees before the training sessions and acquired knowledge after completion of the training sessions. The test questions were based on training contents and the general awareness on WASH subject. The 15 basic questions as shown in Table 1(c) on the subject were tested before and after and change results recorded. The changes of knowledge level on subjects were remarkable and some cases it was about 50 percent. 
Table 1(C): Analysis of Pre -Post Questionnaire used during FLWs(ASHA) training on WASH

\section{Districts of Eastern MP (Satna, Chhatarpur, Rewa, Sidhi, Jabalpur, Mandla \& Damoh)}

\begin{tabular}{|c|c|c|c|c|c|}
\hline \multirow[t]{2}{*}{$\begin{array}{l}\text { Sl. } \\
\text { No }\end{array}$} & \multirow[t]{2}{*}{ Question } & \multirow{2}{*}{$\begin{array}{l}\text { Max. } \\
\text { Mark } \\
\text { s }\end{array}$} & \multicolumn{2}{|c|}{$\begin{array}{l}\begin{array}{l}\text { Average } \quad \text { Score } \\
(\mathrm{N}=8098)\end{array} \\
\end{array}$} & \multirow[t]{2}{*}{$\begin{array}{l}\text { Change } \\
\%\end{array}$} \\
\hline & & & Pre & Post & \\
\hline 1 & $\begin{array}{l}\text { Beneficiary categories under the "Swachh } \\
\text { Bharat Mission" }\end{array}$ & 7 & 2.6 & 4.7 & 29.5 \\
\hline 2 & $\begin{array}{l}\text { Identify the Clean and safe source of } \\
\text { drinking water }\end{array}$ & 5 & 3.2 & 4.4 & 22.5 \\
\hline 3 & $\begin{array}{l}\text { The process to safe drinking water from } \\
\text { contamination }\end{array}$ & 5 & 3.3 & 4.6 & 27.2 \\
\hline 4 & $\begin{array}{l}\begin{array}{l}\text { Identify the diseases spread due to } \\
\text { contaminated water }\end{array} \\
\end{array}$ & 8 & 2.8 & 5.6 & 35.9 \\
\hline 5 & $\begin{array}{l}\text { Types of precaution one should follow } \\
\text { during Diahhorea }\end{array}$ & 4 & 2.5 & 3.9 & 33.2 \\
\hline 6 & $\begin{array}{l}\text { The important occasion /time when one } \\
\text { should be washing hands with soap }\end{array}$ & 5 & 3.2 & 4.8 & 32.2 \\
\hline 7 & $\begin{array}{l}\text { Three major wrong practices making the } \\
\text { village un-hygienic }\end{array}$ & 3 & 1.7 & 2.8 & 35.9 \\
\hline 8 & $\begin{array}{l}\text { Important factors to maintain individual } \\
\text { hygiene }\end{array}$ & 3 & 2.0 & 2.8 & 29.0 \\
\hline 9 & $\begin{array}{l}\text { Constitutional body developed in the } \\
\text { Village level to improve health, hygiene, } \\
\text { and nutrition status of community members }\end{array}$ & 4 & 1.1 & 2.8 & 42.7 \\
\hline 10 & $\begin{array}{l}\text { Methods adopt to make understand your } \\
\text { opinion to an individual }\end{array}$ & 4 & 0.9 & 2.4 & 35.8 \\
\hline 11 & 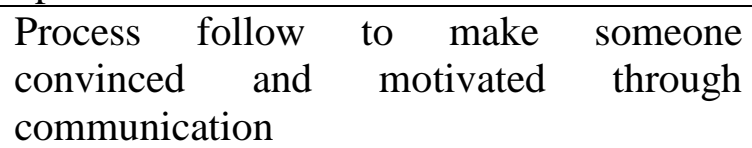 & 4 & 0.9 & 2.3 & 34.3 \\
\hline 12 & Quality of a good adviser & 4 & 1.2 & 2.7 & 37.6 \\
\hline 13 & $\begin{array}{llll}\text { Importance of } & \text { Inter } & \text { Personal } \\
\text { Communication(IPC) } & & \\
\end{array}$ & 3 & 1.0 & 2.1 & 39.4 \\
\hline 14 & $\begin{array}{l}\text { Important points to be followed at the time } \\
\text { of Inter Personal Communication (IPC) }\end{array}$ & 3 & 0.9 & 2.3 & 46.4 \\
\hline 15 & $\begin{array}{l}\text { Points to be considered to make some one } \\
\text { important during discussion }\end{array}$ & 3 & 1.2 & 2.4 & 42.0 \\
\hline
\end{tabular}

The pre-post test results of AWW shown in Table 2(c) were somehow better than the ASHA worker trained under the WASH program. It was found that AWW workers were more organized workforce then the ASHA in 4 Districts of MP. The AWWs would be more effective to communicate the WASH message to the community as well as the objectives of the "Swachh Bharat Mission". 


\begin{tabular}{|c|c|c|c|c|c|}
\hline \multicolumn{6}{|c|}{4 Districts of Eastern MP (Satna, Chhatarpur, Jabalpur \& Damoh) } \\
\hline \multirow[t]{2}{*}{$\begin{array}{l}\text { Sl. } \\
\text { No }\end{array}$} & \multirow[t]{2}{*}{ Question } & \multirow{2}{*}{$\begin{array}{l}\text { Max. } \\
\text { Mar } \\
\text { ks }\end{array}$} & \multicolumn{2}{|c|}{$\begin{array}{l}\text { Average } \\
(\mathrm{N}=6654)\end{array}$} & \multirow[t]{2}{*}{$\begin{array}{l}\text { Change } \\
\%\end{array}$} \\
\hline & & & Pre & Post & \\
\hline 1 & $\begin{array}{l}\text { Beneficiary categories under the "Swachh } \\
\text { Bharat Mission" }\end{array}$ & 7 & 3.3 & 6.9 & 50.9 \\
\hline 2 & $\begin{array}{l}\text { Identify the Clean and safe source of } \\
\text { drinking water }\end{array}$ & 5 & 1.8 & 2.9 & 22.6 \\
\hline 3 & $\begin{array}{l}\text { The process to safe drinking water from } \\
\text { contamination }\end{array}$ & 5 & 3.1 & 4.9 & 34.6 \\
\hline 4 & $\begin{array}{l}\text { Identify the diseases spread due to } \\
\text { contaminated water }\end{array}$ & 8 & 3.5 & 7.7 & 53.1 \\
\hline 5 & $\begin{array}{l}\text { Types of precaution one should follow } \\
\text { during Diahhorea }\end{array}$ & 4 & 2.0 & 3.0 & 24.0 \\
\hline 6 & $\begin{array}{l}\text { The important occasion /time when one } \\
\text { should be washing hands with soap }\end{array}$ & 5 & 3.6 & 4.9 & 27.2 \\
\hline 7 & $\begin{array}{l}\text { Three major wrong practices making the } \\
\text { village un-hygienic }\end{array}$ & 3 & 2.2 & 3.0 & 24.7 \\
\hline 8 & $\begin{array}{l}\text { Important factors to maintain individual } \\
\text { hygiene }\end{array}$ & 3 & 2.1 & 3.0 & 29.3 \\
\hline 9 & $\begin{array}{l}\text { Constitutional body developed in the Village } \\
\text { level to improve health, hygiene, and } \\
\text { nutrition status of community members }\end{array}$ & 4 & 0.7 & 1.0 & 6.2 \\
\hline 10 & $\begin{array}{l}\text { Methods adopt to make understand your } \\
\text { opinion to an individual }\end{array}$ & 4 & 0.6 & 1.0 & 9.9 \\
\hline 11 & $\begin{array}{l}\text { Process follow to make someone convinced } \\
\text { and motivated through communication }\end{array}$ & 4 & 0.5 & 1.0 & 12.8 \\
\hline 12 & Quality of a good adviser & 4 & 2.0 & 3.8 & 46.8 \\
\hline 13 & $\begin{array}{lll}\text { Importance } \quad \text { of } & \text { Inter } & \text { Personal } \\
\text { Communication(IPC) } & & \\
\end{array}$ & 3 & 1.2 & 2.9 & 55.1 \\
\hline 14 & $\begin{array}{l}\text { Important points to be followed at the time } \\
\text { of Inter Personal Communication (IPC) }\end{array}$ & 3 & 1.3 & 2.9 & 52.3 \\
\hline 15 & $\begin{array}{l}\text { Points to be considered to make some one } \\
\text { important during discussion }\end{array}$ & 3 & 1.7 & 2.8 & 37.0 \\
\hline
\end{tabular}

\section{Challenges}

To organize large scale training in rural set up was itself a challenge. The major challenged faced by the teams to organize the training at panchyat and cluster level in rural areas were related to logistic arrangement linked with training i.e. sitting arrangement, drinking water, refreshment for the trainees and transportation of the trainers for timely attained the training. The other challenged was to follow the training pedagogy like to introducing audio-visual instruments to follow the standard teaching \& training materials, share the success stories on the subject, communicating the govt. message and schemes related to the "Swachh Bharat Mission" due to lack of electricity. Though there were number of challenges but with the help of the local 
Panchyat, PHCs and block NHM, the team completed the task in time without compromising the quality issues.

The training team members were taken number of measures to minimize the operational challenges to full fill the training objectives maintaining the standard training protocol/pedagogy. The team developed banner of all the study materials, used laptop with LCD projector where ever electricity was available, printed \& share the handbook for all the trainees to carry out the training messages as well as used as reference materials for mobilization of household in villages. The arrangement like drinking water at training venue, tea \& snacks and staying arrangement of trainers were managed through the coordination with local administration.

\section{Conclusion \& Recommendations}

Drinking water supply, coverage and sanitation in India are continued to be inadequate, despite efforts by the various levels of government departments and communities. India is severely offtrack in reaching the MDG target on sanitation. If the current rate of progress is maintained, it will take 40 more years to meet the target originally set for 2015 . To improve the water, sanitation, and hygiene (WASH) planning, delivery, and monitoring mechanisms, and to accelerate the sanitation coverage through a community-led approach is the priority of the government. It can be possible by the involvement of the community level workers as a change media. The trained FLWs may be in turn become the catalyst to the community members to increase awareness on WASH components, demand creation of Govt. schemes and use of funds for WASH activities etc. The trained FLWs may be used to strengthening the follow up \& monitoring the units of toilets built up under "Swachh Bharat Mission" through the Panchyat Raj System in the community. Under this understanding, IIHMR University team with technical support of MPTAST designed the WASH training plan for the FLWs and provided training in 7 highly vulnerable districts in eastern part of MP on water \& sanitation.

The WASH training was highly appreciated by the FLWs and number of suggestions provided by them to improve the WASH situation in rural districts of Madhya Pradesh. It was clear during discussions with the participants at various stages that the impact of WASH training will be effective to make the required changes only when different line departments work together at the village level in coordination.

To improve the status of WASH in the rural set up, the acceptance of the following recommendations may be trustworthy.

- Strengthening coordination mechanisms at Panchyat level among key govt. development departments i.e. PHED, Panchyat Raj \& Rural Development, Health \& Family Welfare Department, and Women \& Child Development. It is also expecting that WASH program should be linked with health and nutrition issues at local level.

- Panchyat should be more focused on WASH program components, available govt. scheme on conservation \& quality drinking water, maintenance of drainage system and constructing new toilets under "Swachh Bharat Mission program".

- Panchayat should develop monitoring unit of WASH program performance at village level, handle the community grievances on receiving subsidies on construction of toilets, problem faced by an individual on water connection, sewerage, maintenance of 
community Hand Pump, drainage system for better implementation of WASH at ground level.

\section{Acknowledgements}

The author is very much acknowledged the support of "WaterAid" India team members in implementing the WASH trainings in 7 eastern districts of Madhya Pradesh along with the young enthusiast trainers hired as a trainer by IIHMR University. The author is also thankful to the trainees i.e. ASHA \& AWW of the program districts for their kind cooperation and support to the trainers for effectively completion the training within the specified time.

\section{References}

[1] Dr LEE Jong -Wook, Director-General, World Health Organization(WHO) on Water, Sanitation, and Hygiene links to Health.

[2] Chris Bussiere, Drinking Water Contamination

[3] Program Documents of MPWASH : Improving Water, Sanitation \& Hygiene in MP

[4] Luckose Mathew, Team Leader, MPWASH, WaterAid India Fostering institutional transformation in rural India: lessons from MP-WASH program.

[5] IIHMR University, Jaipur. Report on FLWs training on WASH in MP

*Corresponding author.

E-mail address: shyam@ iihmr.edu.in 